\title{
Double balloon catheter for induction of labour in Chinese women with previous caesarean section: one-year experience and literature review
}

\author{
Queenie KY Cheuk *, TK Lo, CP Lee, Anita PC Yeung
}

\section{A B S T R A C T}

Objectives: To evaluate the efficacy and safety of double balloon catheter for induction of labour in Chinese women with one previous caesarean section and unfavourable cervix at term.

Design: Retrospective cohort study.

Setting: A regional hospital in Hong Kong.

Patients: Women with previous caesarean delivery requiring induction of labour at term and with an unfavourable cervix from May 2013 to April 2014.

Major outcome measures: Primary outcome was to assess rate of successful vaginal delivery (spontaneous or instrument-assisted) using double balloon catheter. Secondary outcomes were double balloon catheter induction-to-delivery and removalto-delivery interval; cervical score improvement; oxytocin augmentation; maternal or fetal complications during cervical ripening, intrapartum and postpartum period; and risk factors associated with unsuccessful induction.

Results: All 24 Chinese women tolerated double balloon catheter well. After double balloon catheter expulsion or removal, the cervix successfully ripened in $18(75 \%)$ cases. The improvement in Bishop score 3 (interquartile range, 2-4) was statistically significant $(\mathrm{P}<0.001)$. Overall, 18 (75\%) cases were delivered

This article was published on 22 May 2015 at www.hkmj.org. vaginally. The median insertion-to-delivery and removal-to-delivery intervals were 19 (interquartile range, 13.4-23.0) hours and 6.9 (interquartile range,

4.1-10.8) hours, respectively. Compared with cases without, the interval to delivery was statistically significantly shorter in those with spontaneous balloon expulsion or spontaneous membrane rupture during ripening ( 7.8 vs 3.0 hours; $\mathrm{P}=0.025$ ). There were no major maternal or neonatal complications. The only factor significantly associated with failed vaginal birth after caesarean was previous caesarean section for failure to progress $(\mathrm{P}<0.001)$.

Conclusions: This is the first study using double balloon catheter for induction of labour in Asian Chinese women with previous caesarean section. Using double balloon catheter, we achieved a vaginal birth after caesarean rate of $75 \%$ without major complications.

\section{Hong Kong Med J 2015;21:243-50}

DOI: $10.12809 / \mathrm{hkmj} 144404$

${ }^{1}$ QKY Cheuk *, MB, ChB, FHKAM (Obstetrics and Gynaecology)

${ }^{2}$ TK Lo, MB, BS, FHKAM (Obstetrics and Gynaecology)

${ }^{2}$ CP Lee, FRCOG, FHKAM (Obstetrics and Gynaecology)

${ }^{1}$ APC Yeung, FRCOG, FHKAM (Obstetrics and Gynaecology)

Department of Obstetrics and Gynaecology, Pamela Youde Nethersole Eastern Hospital, Chai Wan, Hong Kong

2 Department of Obstetrics and Gynaecology, Queen Mary Hospital, The University of Hong Kong, Pokfulam, Hong Kong

* Corresponding author: cheuky3@ha.org.hk

New knowledge added by this study

- This is the first report from Asian Chinese women on the use of double balloon catheter (DBC) for induction of labour in the presence of a caesarean scar. Using DBC, a vaginal birth after caesarean (VBAC) rate of $75 \%$ was achieved without major complications.

- During cervical ripening with DBC, cases with spontaneous balloon expulsion or spontaneous membrane rupture had a more favourable outcome with shorter interval to delivery.

- Previous caesarean section for failure to progress was significantly associated with failed VBAC.

Implications for clinical practice or policy

- Our anecdotal experience with DBC was favourable and its application may reduce repeated caesarean section rates. Further research exploring this potential is warranted and large randomised controlled trials are needed to confirm its efficacy.

\section{Introduction}

There is widespread public and professional concern about the increasing rates of caesarean section (CS). In the UK and North America, around 25\% and 32\% of births respectively were by CS. ${ }^{1,2}$ In Hong Kong, according to the 2009 territory-wide O\&G audit report, CS rate has been around $42.1 \%{ }^{3}$ Previous CS has been the most common indication for caesarean 


\section{以雙球囊導管為曾有剖腹產病史的華籍女性進行 引產：一年經驗分享及文獻綜述 \\ 卓筠嬈、盧子健、李之朋、楊寶芝}

目的：以雙球囊導管為曾有一次剖腹產病史和宮頸不成熟的華籍女性 施行引產, 評估其療效和安全性。

設計：回顧性隊列研究。

安排 : 香港一所分區醫院。

患者：2013年5月至2014年4月期間曾進行剖腹產並於足月引產前宮 頸不成熟的女性。

主要結果測量：主要療效指標為使用雙球囊導管而達至陰道分娩的成 功比率（包括自然分婏或使用儀器助產）。次要療效指標為從置入直 至分娩時移除雙球囊導管的時間差距、宮頸成熟度評分的改善、催產 素的使用、產婦或胎兒在使用雙球囊導管引產以及分娩時和產後所出 現的併發症, 並引產失敗的風險因素。

結果：全部24名華籍女性對於雙球囊導管的耐受性良好。雙球囊導管 自行排出或被取出時, 有18例（75\%）促宮頸成熟成功。使用雙球囊 導管使宮頸成熟度（Bishop）評分改善中位數為3分（四分位距：2-4 分）的病例有顯著改善 $(\mathrm{P}<0.001)$ 。總體而言，18例（75\%）成功 經陰道分婏。置入雙球囊導管至分婏的時間中位數為19小時（四分 位距：13.4-23.0小時）, 取出雙球囊導管至分娩的時間中位數為6.9 小時（四分位距：4.1-10.8小時）。與沒有自行排出球囊或胎膜自破 的參與者比較, 自行排出球囊或胎膜自破的參與者的分婏時間明顯較 短：7.8比3.0小時（ $\mathrm{P}=0.025 ）$ 。使用雙球囊導管並無發生嚴重的產 婦或新生兒併發症。唯一與剖腹產後陰道分娩失敗明顯有關的因素為 曾經因產程進展不良而進行剖腹產（ $\mathrm{P}<0.001 ） 。$

結論：這是為曾經進行剖腹產的亞洲婦女使用雙球囊導管催生引產的 首項研究。採用雙球囊導管後, 有 $75 \%$ 成功以陰道分娩而無嚴重併發 症。 in room temperature. Compared to conventional Foley catheter, the double balloon catheter (DBC) has a cervicovaginal balloon in addition, allowing greater compression of the cervical os and avoiding the need for traction (Fig 1). Nevertheless, there are limited reports about the experience with the use of DBC. Regarding the question of which IOL method is suitable in women with prior CS, a recent Cochrane review stated that there was insufficient information available to conclude on the optimal method of IOL in women with prior CS. ${ }^{7}$

Since May 2013, our unit has been offering the option of DBC (Cook Cervical Ripening Balloon; Cook Medical, Bloomington [IN], US) for IOL in women with one previous CS. Therefore, we conducted a study on Chinese women with an objective to evaluate the efficacy and safety of the $\mathrm{DBC}$ in IOL with one previous CS and unfavourable cervix at term. Another objective was to identify risk factors associated with unsuccessful VBAC. This is one of the first studies to report using $\mathrm{DBC}$ for this indication in Asian Chinese population.

\section{Methods}

This retrospective study was conducted in the obstetrics unit of Pamela Youde Nethersole Eastern Hospital in Hong Kong. The unit provides tertiary care and conducts over 3000 deliveries per year. Prior to the introduction of $\mathrm{DBC}$, the background CS and VBAC rates in our unit was approximately $30 \%$ and $1.9 \%$, respectively. The overall success rate of VBAC was more than $80 \%$. In our study, we identified VBAC cases using DBC for IOL between 1 May 2013 and 30 April 2014 through the departmental database. Clinical details were reviewed from the case notes and hospital electronic systems.

delivery. ${ }^{3}$ In subsequent pregnancies, CS can be associated with serious maternal morbidities. ${ }^{4}$ To reduce $C S$ rate and related morbidities, vaginal birth after caesarean (VBAC) is an alternative advocated in most developed countries. ${ }^{2,5,6}$ According to the UK and North American guidelines, induction of labour (IOL) can be offered to women with medical or obstetric indications who opt for VBAC after discussion. ${ }^{2,5}$

Unfavourable cervix, which is a common obstetric problem, can be addressed using pharmacological and mechanical methods to enable cervical ripening. In Hong Kong pharmacological method is more commonly used for IOL. In women with previous CS, the increased risk of uterine rupture is a major concern during IOL. ${ }^{2,5-7}$ Mechanical methods apply pressure on the internal cervical os, stretch the lower uterine segment, and increase local production of prostaglandin. There is a lack of compelling evidence suggesting increased risk of uterine rupture because mechanical devices can be readily removed when needed and are stable

\section{Inclusion and exclusion criteria}

Inclusion criteria were women with one lower transverse caesarean scar and no contra-indication for VBAC who were given the option of either repeated elective CS or VBAC. Those VBAC cases requiring medically or obstetrically indicated IOL

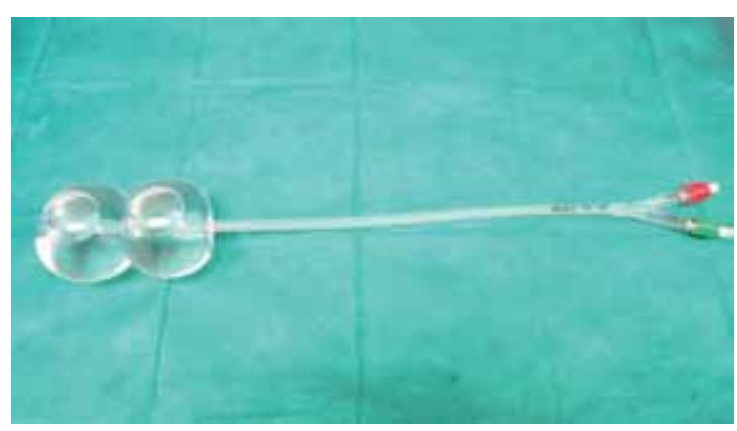

FIG I. Double balloon catheter 
were offered DBC if the cervix was unfavourable (modified Bishop score $<6$ ) and membranes intact.

The exclusion criteria for using $\mathrm{DBC}$ were: women with two or more previous CS, classical CS scar, inverted $\mathrm{T}$ or $\mathrm{J}$ or low vertical incision in previous CS; previous uterine scar for gynaecological conditions, eg myomectomy, hysterotomy; congenital uterine abnormality; twin pregnancy, non-cephalic presentations, intra-uterine death, suspected fetal distress; uterine fibroids which may obstruct labour, placenta praevia, antepartum haemorrhage, leaking, clinical chorioamnionitis, suspected macrosomia (ultrasound estimated fetal weight $\geq 4000 \mathrm{~g}$ ), polyhydramnios (amniotic fluid index $\geq 25 \mathrm{~cm}$ or single deepest pocket $\geq 8 \mathrm{~cm}$ ), congenital fetal abnormalities; and maternal diseases or maternal infection which would contra-indicate vaginal delivery or warrant prompt delivery. Ethical approval for this study was obtained from the local institutional human research ethics committee.

\section{Induction-of-labour protocol}

Eligible patients were admitted into hospital in the evening and an initial Bishop score was obtained. Cardiotocogram for 60 minutes, and ultrasound scan to assess estimated fetal weight, liquor volume, fetal wellbeing by umbilical artery Doppler and placental location were performed. After informed consent, the $\mathrm{DBC}$ was inserted according to the manufacturer's instruction. If the $\mathrm{DBC}$ insertion failed, women would be offered CS the next day morning. The procedure of $\mathrm{DBC}$ insertion in all patients was done by one investigator (KY Cheuk). The uterine and vaginal balloons were inflated in phases to $40-50 \mathrm{~mL}$ and $60 \mathrm{~mL}$, respectively using normal saline. After insertion, vaginal examination was performed to confirm correct placement. The catheter was taped to the woman's inner thigh without tension. Following insertion of catheter, continuous fetal heart monitoring (CFHM) was done for 60 minutes. The catheter was kept for 12 hours if spontaneous expulsion did not occur, or removed earlier if there was spontaneous rupture of membranes, excessive vaginal bleeding, fetal distress, scar tenderness, or patient intolerance. Immediately following balloon expulsion or removal, the Bishop score was reassessed, followed by an attempt to have artificial rupture of membranes (ARM) regardless of Bishop score. To reduce the potential inter-observer bias, the same investigator (KY Cheuk) assessed the Bishop score before DBC insertion and immediately after DBC expulsion or removal. Oxytocin infusion (Syntocinon; Sandoz Pharmaceuticals, East Hanover [NJ], US) was commenced if after ARM the uterine contractions remained suboptimal at a rate of $1 \mathrm{mU} / \mathrm{min}$ and the infusion rate was doubled every 30 minutes until the uterine contractions were regular at 3 minutes' interval. The maximum dose was capped at $8 \mathrm{mU} / \mathrm{min}$. Oxytocin was not started without membrane rupture or if the DBC was still in place; CFHM was started after ARM till delivery. Labour was managed by the attending obstetrician and midwives. Assessment of labour progress and administration of analgesia was made according to departmental protocols. Group B streptococcus prophylaxis was given according to departmental protocol. It was commenced after DBC insertion until delivery for group B streptococcus carriers.

\section{Outcome measures}

The primary outcome was successful vaginal delivery (spontaneous or instrument-assisted). The secondary outcomes were: induction-to-delivery interval; device-removal-to-delivery interval; cervical score improvement; oxytocin augmentation; maternal or fetal complications during cervical

TABLE I. Baseline characteristics of women with previous caesarean section induced with double balloon catheter

\begin{tabular}{|c|c|}
\hline Characteristic & Data* \\
\hline Age (years) & $35(32.5-36.3)$ \\
\hline Height (cm) & $159.0(154.0-161.0)$ \\
\hline BMI $\left(\mathrm{kg} / \mathrm{m}^{2}\right)$ & $22.6(20.6-26.4)$ \\
\hline Parity & $1(1-1)$ \\
\hline \multicolumn{2}{|l|}{ Obstetric history } \\
\hline Previous vaginal delivery & $4(16.7)$ \\
\hline Successful VBAC & $1(4.2)$ \\
\hline \multicolumn{2}{|l|}{ Indication of previous caesarean section } \\
\hline Failed to progress & 8 (33.3) \\
\hline Malpresentation & $7(29.2)$ \\
\hline Placenta praevia & $2(8.4)$ \\
\hline Others $†$ & $7(29.2)$ \\
\hline \multicolumn{2}{|l|}{ Current pregnancy } \\
\hline Duration from last caesarean delivery (years) & $5.5(3.0-7.3)$ \\
\hline Gestation at labour induction (weeks) & $39.1(38.7-39.6)$ \\
\hline Cervical Bishop score before induction & $3(3-4)$ \\
\hline GBS carrier & $6(25)$ \\
\hline \multicolumn{2}{|l|}{ Indication for induction } \\
\hline GDM & $8(33.3)$ \\
\hline Past-term ( $\geq 40$ weeks) & $7(29.2)$ \\
\hline Decreased fetal movement & $4(16.7)$ \\
\hline Oligohydramnios & $2(8.3)$ \\
\hline Bad obstetric history & $1(4.2)$ \\
\hline
\end{tabular}

Abbreviations: $\mathrm{BMI}=$ body mass index; $\mathrm{GBS}=$ group $\mathrm{B}$ streptococcus; $\mathrm{GDM}=$ gestational diabetes mellitus; VBAC = vaginal birth after caesarean section

* Data are shown as median (interquartile range), or No. (\%)

+ One case each for fetal distress, cord round neck, large for gestational age with GDM, large head circumference, prolonged leaking, meconium-stained liquor, and bad obstetric history 
ripening, intrapartum and postpartum period, which included failed device insertion, inability to void during insertion, intolerance of device necessitating early removal, uterine hyperstimulation, uterine rupture, fetal distress, abruption, antepartum haemorrhage, cord prolapse, malpresentation, meconium-stained liquor, intrapartum and postpartum infection, postpartum haemorrhage, readmission in puerperium period, neonate delivery with Apgar score of $<7$ in 5 minutes, cord blood pH of $<7.2$, admission to neonatal intensive care unit, neonatal sepsis, respiratory distress syndrome and neonatal death, and risk factors associated with unsuccessful induction.

Uterine hyperstimulation was defined as either the occurrence of five or more contractions in 10 minutes for two consecutive 10-minute period, or a contraction lasting for at least 2 minutes, with or without changes in fetal heart rate pattern. Uterine rupture was defined as disruption of the uterine muscle extending to and involving the uterine serosa or disruption of the uterine muscle with extension to the bladder or broad ligament. ${ }^{5}$ Uterine dehiscence was defined as disruption of the uterine muscle with intact uterine serosa. ${ }^{5}$ Intrapartum infection was defined by maternal fever of $\geq 38^{\circ} \mathrm{C}$ during labour. Failed IOL was defined as failed ARM after catheter removal or cervical dilatation of $<3 \mathrm{~cm}$ after at least 8 hours of optimal uterine contractions.

\section{Literature review}

We also conducted a literature search on PubMed, Ovid Medline, EMBASE, Cochrane library database

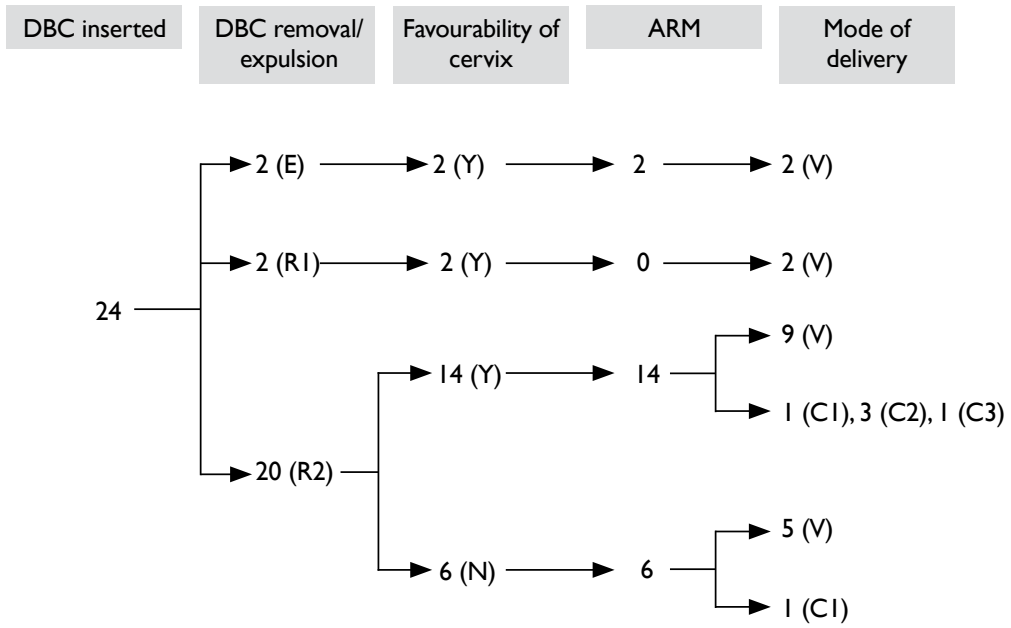

FIG 2. Labour induction with double balloon catheter

Abbreviations: ARM = artificial rupture of membranes; $\mathrm{Cl}$ = caesarean for failure to progress; $\mathrm{C2}$ = caesarean for pathological fetal heart tracings; $\mathrm{C} 3=$ caesarean for suspected scar dehiscence; DBC = double balloon catheter; $\mathrm{E}=$ expulsion; $\mathrm{N}=$ unfavourable cervix (Bishop score <6); RI = removal for SROM; R2 = removal at 12 hours; $S R O M=$ spontaneous rupture of membranes; $\vee=$ vaginal; $Y=$ favourable cervix (Bishop score $\geq 6$ ) of systematic reviews and open library using the keywords "double balloon catheter", "Atad balloon", "double balloon device", "Foley catheter", "induction", "previous caesarean section", and "previous scarred uterus". Bibliographies of all relevant articles identified were searched manually to locate additional studies. We excluded non-English publications, or if the original paper was not available from various sources such as PubMed, local hospital or universities library systems and internet.

\section{Statistical analyses}

The statistical analysis was done by PASW Statistics 18, Release Version 18.0.0 (SPSS Inc, 2009, Chicago [IL], US). Fisher's exact test was used for categorical data, while independent $t$ test was used if normally distributed, and non-parametric test (ie MannWhitney $U$ test) if highly skewed. Univariate analysis was used to assess the risk factors associated with unsuccessful VBAC. To identify the differential effect over time, Wilcoxon signed rank test was used to compare the cervical Bishop scores before and after DBC application. The critical level of statistical significance was set at $\mathrm{P}<0.05$.

\section{Results}

Twenty-five cases were identified during the 1-year study period, and one non-Chinese woman's data were excluded. The remaining 24 cases were included for analysis. Table 1 summarises the baseline characteristics of study patients.

Figure 2 depicts the induction process and outcomes of the 24 cases; DBC was well tolerated in all cases (Table 2). There was no case of failed insertion. After DBC expulsion or removal, the cervix became favourable (Bishop's score $\geq 6$ ) in $18(75 \%)$ cases. The improvement in Bishop score 3 (interquartile range [IQR], 2-4) was statistically significant $(\mathrm{P}<0.001)$. Artificial rupture of the membranes was successful in all 22 cases with intact membranes, regardless of cervical favourability. Oxytocin augmentation was required in 18 (75\%) cases. Overall, $75 \%$ of cases were delivered vaginally. Among them, the median insertion-to-delivery and removal-to-delivery intervals were 19 (IQR, 13.4-23.0) hours and 6.9 (IQR, 4.1-10.8) hours, respectively. All the four women with previous vaginal deliveries had successful VBAC. Compared with cases without, the balloon expulsion-todelivery or removal-to-delivery interval was shorter in those with spontaneous balloon expulsion or early balloon removal due to spontaneous membrane rupture during ripening ( 7.8 vs 3.0 hours, $\mathrm{P}=0.025)$. All the cases had good neonatal outcomes with cord blood $\mathrm{pH}$ of $>7.25$, 5-minute Apgar score of 10, without the need for neonatal intensive care unit admissions (Table 3). One case reported severe scar 
TABLE 2. Labour and delivery outcomes after induction of labour with DBC

\begin{tabular}{|c|c|c|}
\hline From DBC insertion to its removal/expulsion & Data* & $P$ value \\
\hline DBC-related complications $†$ & $0(0)$ & \\
\hline \multicolumn{3}{|l|}{ After DBC removal/expulsion } \\
\hline Cervical Bishop score & $7(5.3-8.0)$ & \\
\hline Change in Bishop score & $3(2-4)$ & $<0.001 \ddagger$ \\
\hline Cervix successfully ripen§ & $18(75)$ & \\
\hline ARM required & $22(92)$ & \\
\hline ARM successful & $22(100)$ & \\
\hline Oxytocin augmentation required & $18(75)$ & \\
\hline Analgesic required ॥ & $18(75)$ & \\
\hline EA & $1(4)$ & \\
\hline \multicolumn{3}{|l|}{ Mode of delivery } \\
\hline Vaginal deliveries $\mathbb{1}$ & $18(75)$ & \\
\hline DBC-insertion-to-delivery interval (hours) & $19.0(13.4-23.0)$ & \\
\hline DBC-removal/expulsion-to-delivery interval (hours) & $6.9(4.1-10.8)$ & \\
\hline Those requiring $\mathrm{DBC}$ removed at 12 hours & $7.8(5.3-12.1)$ & \\
\hline Those with DBC expelled/removed due to SROM & $3.0(1.1-5.7)$ & $0.025^{\star *}$ \\
\hline Caesarean section & $6(25)$ & \\
\hline Pathological fetal heart tracings & $3(13)$ & \\
\hline Failure to progress & 2 (8) & \\
\hline Suspected scar dehiscence & $1(4)$ & \\
\hline
\end{tabular}

Abbreviations: $\mathrm{ARM}=$ artificial rupture of membranes; $\mathrm{DBC}=$ double balloon catheter; $\mathrm{EA}$ = epidural analgesia; $\mathrm{SROM}=$ spontaneous rupture of membranes

* Data are shown as median (interquartile range), or No. (\%)

$\dagger$ Included failed insertion, uterine hyperstimulation, fever, inability to void, scar tenderness, intolerance necessitating early removal, and fetal distress when DBC was in place

‡ Wilcoxon signed rank test

$\S$ Defined as Bishop's score $\geq 6$

II Including pethidine injection, Entonox, EA

II Including 2 instrumental deliveries: I for prolonged second stage and the other for pathological fetal heart tracings

*** Mann-Whitney $U$ test

pain during oxytocin augmentation. Scar dehiscence was suspected and emergency CS performed. Dehiscence was not substantiated intra-operatively. The baby was born in good condition. Apart from a few cases of maternal complications (eg postpartum infection and postpartum haemorrhage), there was no case of uterine rupture or adverse neonatal complications.

To study the risk factors associated with unsuccessful VBAC, univariate analysis was performed using maternal age, height, body mass index, cervical Bishop score, cervical favourability after DBC removal or dislodgement, gender and birth weight of baby, gestational diabetes mellitus, history of vaginal delivery, history of successful VBAC, inter-pregnancy interval, the indication for previous CS, and the indication for IOL in the current pregnancy as variables. Previous CS for failure to progress was the only factor significantly associated with unsuccessful VBAC $(\mathrm{P}<0.001)$.

\section{Discussion}

Few studies have investigated the use of $\mathrm{DBC}$ for IOL in patients with previous caesarean scars. Table 4 summarises the findings from some of the studies $^{8-11}$ including the current study. Most of the studies showed significant improvement in Bishop score after using the device and a favourable cervix was achieved in $75 \%$ to $85 \%$ of cases. The overall vaginal delivery rate was $60.2 \%(71 / 118)$. There was one $(0.85 \%)$ case of symptomatic scar dehiscence, and no adverse neonatal complications. The cervical ripening success rate in our study was comparable to those in other studies, and also our study achieved a higher vaginal delivery rate. One explanation for this would have been due to differences in the IOL protocols. Some authors would offer CS directly if the cervix failed to ripen after the DBC. ${ }^{9}$ Our practice was to continue induction with ARM and oxytocin even if the cervix remained unfavourable 
TABLE 3. Maternal complications and neonatal outcomes after induction of labour with double balloon catheter

\begin{tabular}{|c|c|}
\hline $\begin{array}{l}\text { Maternal complications and } \\
\text { neonatal outcomes }\end{array}$ & Data* \\
\hline \multicolumn{2}{|l|}{ Maternal complications } \\
\hline Uterine rupture & 0 \\
\hline Uterine hyperstimulation & 0 \\
\hline Meconium-stained liquor & $2(8.3)$ \\
\hline $\mathrm{PPH}$ & $3(12.5)$ \\
\hline \multicolumn{2}{|l|}{ Infection } \\
\hline Intrapartum $\ddagger$ & 0 \\
\hline Postpartum§ & $2(8.3)$ \\
\hline Urinary tract infection & $1(4.2)$ \\
\hline Gaped wound & $1(4.2)$ \\
\hline Others ॥ & 0 \\
\hline \multicolumn{2}{|l|}{ Neonatal outcomes } \\
\hline Birth weight (g) & 3087.5 (2958.8-3350.0) \\
\hline Neonatal complications $\rrbracket$ & 0 \\
\hline \multicolumn{2}{|c|}{$\begin{array}{l}\text { Abbreviation: } \mathrm{PPH}=\text { postpartum haemorrhage } \\
\text { * Data are shown as median (interquartile range), or No. (\%) } \\
\text { † } \mathrm{PPH} \text { range, } 590-850 \mathrm{~mL} \\
\neq \text { Defined by intrapartum fever of } \geq 38^{\circ} \mathrm{C} \\
\text { § Including urinary tract infection and gaped wound } \\
\text { II Including abruption, antepartum haemorrhage, cord } \\
\text { prolapsed, malpresentation, re-admission in puerperium } \\
\text { period } \\
\text { II Including Apgar score of }<7 \text { in } 5 \text { minutes, cord blood } \mathrm{pH} \\
\text { of }<7.2 \text {, admission to neonatal intensive care unit, neonatal } \\
\text { sepsis, respiratory distress syndrome, and neonatal death }\end{array}$} \\
\hline
\end{tabular}

after the DBC. In our patients, $83.3 \%(5 / 6)$ in this group delivered vaginally with continued induction. A second potential reason for better outcomes in our study would lie in the differences in inclusion criteria. Some studies had excluded women with previous vaginal delivery, ${ }^{10}$ a factor known to be associated with successful VBAC. A third reason could have been differences in ethnicity. Studies have shown that ethnicity does impact VBAC success rates. ${ }^{12}$

With increasing rates of CS worldwide, it is estimated that $10 \%$ of women requiring IOL have a history of CS. However, the optimal induction method for this high-risk group is unknown. To counter unfavourable cervix with intact membranes, prostaglandins and mechanical methods such as Foley or DBC have been used. Prostaglandins appeared to be associated with a higher uterine rupture risk. ${ }^{13,14}$ Ravasia et $\mathrm{al}^{14}$ found that the relative risk of uterine rupture with prostaglandins versus spontaneous labour was 6.41, whereas the risk with the use of Foley catheter was comparable to spontaneous labour. Although infective morbidity associated with mechanical induction is a concern, the evidence is contradictory. ${ }^{15,16}$ A systematic review by Heinemann et $\mathrm{al}^{15}$ on studies using Foley catheter for IOL showed that use of mechanical devices was associated with significant increase in maternal morbidity due to infectious morbidity when compared with pharmacological agents. On the other hand, a recent Cochrane review showed no increase in serious maternal morbidity with the use of the Foley catheter. ${ }^{7}$ Further support was provided from the recent open-label randomised controlled trial PROBAAT, ${ }^{16}$ which compared Foley catheter to vaginal prostaglandin in 824 women without previous CS. The study showed that Foley catheter had similar CS rates, less uterine hyperstimulation, fewer maternal and fetal morbidities, and no increase in infectious morbidity. Although Foley catheter was featured in all these studies, DBC potentially has additional utility for an unripe cervix as it applies pressure on both the external and internal os, avoiding the need for traction and reduces the associated patient discomfort. Double balloon catheter has a larger inflated volume compared with Foley catheter $(80 \mathrm{~mL}$ vs $30 \mathrm{~mL})$ and therefore IOL with a bigger balloon volume may shorten duration of labour with better cervical dilatation. ${ }^{17}$ Nevertheless, clinical data comparing DBC with Foley catheter in the presence of a caesarean scar are lacking, while those on intact uterus are scarce and inconclusive. $^{18,19}$

Table 4 summarises the results of studies using Foley catheter for IOL in the presence of a caesarean scar. ${ }^{14,20-24}$ It appears that DBC achieved comparable vaginal delivery rate $(60.2 \%$ vs $58.0 \%)$ and similar uterine rupture/dehiscence rate $(0.85 \%$ vs $0.65 \%)$. There was no case report of neonatal death in studies using DBC while there were two cases reported with Foley catheter. One was due to uterine rupture; another was due to rupture of vasa praevia which was independent of the method of induction. ${ }^{23}$ Further research to compare the efficiency and safety of the two devices for IOL in women with previous CS is warranted. Although uterine rupture and infectious morbidity seemed rare with DBC in women with previous CS, the number of women studied was too small to allow solid conclusion on its safety.

The complication rate for VBAC attempt was highest in those who failed to achieve VBAC in the end. ${ }^{25}$ Knowledge of the factors associated with successful VBAC would therefore enable better counselling on the choice of mode of delivery. Landon et $\mathrm{al}^{12}$ in a large cohort of 14529 women showed that previous vaginal delivery and previous successful VBAC were the best predictors of successful VBAC; the success rates were $86.6 \%$ and $89.6 \%$, respectively. In our study, all four cases with previous vaginal delivery (including one with previous VBAC) had successful VBAC. In the study by Landon et al, ${ }^{12}$ factors associated with unsuccessful VBAC included 
TABLE 4. Analysis of studies using DBC and Foley catheter for IOL in women with previous caesarean section ${ }^{8-11,14,20-24}$

\begin{tabular}{|c|c|c|c|c|c|}
\hline & Year & No. of cases & No. of vaginal deliveries & Success rate $(\%)$ & Complications \\
\hline \multicolumn{6}{|l|}{ DBC } \\
\hline Khotaba et $\mathrm{al}^{8}$ & 2001 & 37 & 24 & 64.9 & 3 Could not tolerate device \\
\hline Miller and Davis ${ }^{9}$ & 2005 & 8 & 2 & 25.0 & 1 Could not tolerate device \\
\hline Ferradas et $\mathrm{al}^{10}$ & 2013 & 32 & 18 & 56.3 & $\begin{array}{l}1 \text { Uterine scar dehiscence } \\
7 \text { Intrapartum fever* } \\
3 \text { Chorioamnionitis } †\end{array}$ \\
\hline Ebeid and Nassif ${ }^{11}$ & 2013 & 17 & 9 & 52.9 & $1 \mathrm{PPH} \ddagger$ \\
\hline Present study & 2015 & 24 & 18 & 75.0 & $\begin{array}{l}3 \text { PPH } \ddagger \\
2 \text { Postpartum infection§ }\end{array}$ \\
\hline Overall & & 118 & 71 & 60.2 & $1(0.85 \%)$ Uterine scar dehiscence \\
\hline \multicolumn{6}{|l|}{ Foley } \\
\hline Ravasia et $\mathrm{al}^{14}$ & 2000 & 129 & 79 & 61.2 & 1 Uterine rupture \\
\hline Ben-Aroya et $\mathrm{al}^{20}$ & 2002 & 161 & 82 & 50.9 & 0 Uterine rupture \\
\hline Bujold et $\mathrm{al}^{21}$ & 2004 & 255 & 142 & 55.7 & 4 Uterine rupture \\
\hline Ziyauddin et $\mathrm{al}^{22}$ & 2013 & 35 & 25 & 71.4 & 0 Uterine rupture \\
\hline Jozwiak et $\mathrm{al}^{23}$ & 2014 & 208 & 148 & 71.2 & $\begin{array}{l}1 \text { Uterine rupture } \\
2 \text { NND }\end{array}$ \\
\hline Sananès et $\mathrm{al}^{24}$ & 2014 & 135 & 59 & 43.7 & 0 Uterine rupture \\
\hline Overall & & 923 & 535 & 58.0 & $\begin{array}{l}6(0.65 \%) \text { Uterine rupture } \\
2 \text { NND }\end{array}$ \\
\hline
\end{tabular}

Abbreviations: $\mathrm{DBC}=$ double balloon catheter; $\mathrm{IOL}=$ induction of labour; $\mathrm{NND}=$ neonatal death; $\mathrm{PPH}=$ postpartum haemorrhage

* Intrapartum fever: body temperature of $\geq 37.8^{\circ} \mathrm{C}$ during labour

+ Chorioamnionitis diagnosed by histological analysis of placenta

$\neq$ Blood loss $\geq 500 \mathrm{~mL}$

$\S$ Included urinary tract infection and gaped wound

obesity, previous CS for dystocia, IOL, birth weight of $>4000 \mathrm{~g}$, advanced maternal age, short stature, more than 2 years from previous caesarean, gestational age of $\geq 41$ weeks, and previous preterm CS. Despite our small sample size, we concurred that previous CS for failure to progress was a significant factor associated with unsuccessful VBAC.

\section{Conclusions}

This is the first report from East Asia on the use of DBC for IOL in the presence of caesarean scar. A success rate of $75 \%$ was achieved using VBAC in Chinese women with a caesarean scar and an unfavourable cervix. The procedure of DBC was well tolerated, and no major complications were observed. Our favourable experience with DBC in Asian Chinese women lends support to further research exploring the potential of this promising modality in averting the rising CS rates in this part of the world.

\section{References}

1. Caesarean section. NICE Clinical Guidelines. National Collaborating Centre for Women's and Children's Health
(UK). London: RCOG Press; November 2011.

2. Vaginal birth after previous Caesarean delivery. ACOG Practice Bulletin. No. 115. American College of Obstetricians and Gynecologists; August 2010.

3. HKCOG Territory-wide O\&G Audit Report: Caesarean section. Hong Kong: Hong Kong College of Obstetricians and Gynaecologists; 2009.

4. Bates GW Jr, Shomento S. Adhesion prevention in patients with multiple cesarean deliveries. Am J Obstet Gynecol 2011;205(6 Suppl):S19-24.

5. Birth after previous Caesarean birth. RCOG Green-top Guideline No. 45. Royal College of Obstetricians and Gynaecologists; February 2007.

6. Society of Obstetricians and Gynaecologists of Canada. SOGC clinical practice guidelines. Guidelines for vaginal birth after previous caesarean birth. Number 155 (Replaces guideline Number 147), February 2005. Int J Gynaecol Obstet 2005;89:319-31.

7. Jozwiak M, Dodd JM. Methods of term labour induction for women with a previous caesarean section. Cochrane Database Syst Rev 2013;(3):CD009792.

8. Khotaba S, Volfson M, Tarazova L, et al. Induction of labor in women with previous cesarean section using the double balloon device. Acta Obstet Gynecol Scand 2001;80:10412 .

9. Miller TD, Davis G. Use of the Atad catheter for the induction of labour in women who have had a previous 
Caesarean section-a case series. Aust N Z J Obstet Gynaecol 2005;45:325-7.

10. Ferradas E, Alvarado I, Gabilondo M, Diez-Itza I, GarcíaAdanez J. Double balloon device compared to oxytocin for induction of labour after previous caesarean section. Open J Obstet Gynecol 2013;3:212-6.

11. Ebeid E, Nassif N. Induction of labor using double balloon cervical device in women with previous cesarean section: experience and review. Open J Obstet Gynecol 2013;3:301 5.

12. Landon MB, Leindecker S, Spong CY, et al. The MFMU Cesarean Registry: factors affecting the success of trial of labor after previous cesarean delivery. Am J Obstet Gynecol 2005;193:1016-23.

13. Lydon-Rochelle M, Holt VL, Easterling TR, Martin DP. Risk of uterine rupture during labor among women with a prior cesarean delivery. N Engl J Med 2001;345:3-8.

14. Ravasia DJ, Wood SL, Pollard JK. Uterine rupture during induced trial of labor among women with previous cesarean delivery. Am J Obstet Gynecol 2000;183:1176-9.

15. Heinemann J, Gillen G, Sanchez-Ramos L, Kaunitz AM. Do mechanical methods of cervical ripening increase infectious morbidity? A systematic review. Am J Obstet Gynecol 2008;199:177-87.

16. Jozwiak M, Oude Rengerink K, Benthem M, et al. Foley catheter versus vaginal prostaglandin E2 gel for induction of labour at term (PROBAAT trial): an open-label, randomized controlled trial. Lancet 2011;378:2095-103.

17. Levy R, Kanengiser B, Furman B, Ben Arie A, Brown D, Hagay ZJ. A randomized trial comparing a $30-\mathrm{mL}$ and an 80-mL Foley catheter balloon for preinduction cervical ripening. Am J Obstet Gynecol 2004;191:1632-6.

18. Salim R, Zafran N, Nachum Z, Garmi G, Kraiem N, Shalev E. Single-balloon compared with double-balloon catheters for induction of labor: a randomized controlled trial. Obstet Gynecol 2011;118:79-86.

19. Mei-Dan E, Walfisch A, Valencia C, Hallak M. Making cervical ripening EASI: a prospective controlled comparison of single versus double balloon catheters. J Matern Fetal Neonatal Med 2014;27:1765-70.

20. Ben-Aroya Z, Hallak M, Segal D, Friger M, Katz M, Mazor M. Ripening of the uterine cervix in a post-cesarean parturient: prostaglandin E2 versus Foley catheter. J Matern Fetal Neonatal Med 2002;12:42-5

21. Bujold E, Blackwell SC, Gauthier RJ. Cervical ripening with transcervical foley catheter and the risk of uterine rupture. Obstet Gynecol 2004;103:18-23.

22. Ziyauddin F, Hakim S, Beriwal S. The transcervical foley catheter versus the vaginal prostaglandin e2 gel in the induction of labour in a previous one caesarean section-a clinical study. J Clin Diagn Res 2013;7:140-3.

23. Jozwiak M, van de Lest HA, Burger NB, Dijksterhuis MG, De Leeuw JW. Cervical ripening with Foley catheter for induction of labor after cesarean section: a cohort study. Acta Obstet Gynecol Scand 2014;93:296-301.

24. Sananès N, Rodriguez M, Stora C, et al. Efficacy and safety of labour induction in patients with a single previous Caesarean section: a proposal for a clinical protocol. Arch Gynecol Obstet 2014;290:669-76.

25. Landon MB, Hauth JC, Leveno KJ, et al. Maternal and perinatal outcomes associated with a trial of labor after prior cesarean delivery. N Engl J Med 2004;351:2581-9. 